\title{
Author Correction: GWAS of thyroid stimulating hormone highlights the pleiotropic effects and inverse association with thyroid cancer
}

Wei Zhou (1), Ben Brumpton (1), Omer Kabil, Julius Gudmundsson, Gudmar Thorleifsson, Josh Weinstock (D), Matthew Zawistowski (D), Jonas B. Nielsen (D), Layal Chaker, Marco Medici, Alexander Teumer (D), Silvia Naitza, Serena Sanna (1), Ulla T. Schultheiss, Anne Cappola, Juha Karjalainen, Mitja Kurki, Morgan Oneka (1), Peter Taylor, Lars G. Fritsche (1), Sarah E. Graham (1), Brooke N. Wolford (1), William Overton, Humaira Rasheed (1),

Eirin B. Haug, Maiken E. Gabrielsen, Anne Heidi Skogholt, Ida Surakka, George Davey Smith (1), Anita Pandit, Tanmoy Roychowdhury, Whitney E. Hornsby, Jon G. Jonasson, Leigha Senter, Sandya Liyanarachchi, Matthew D. Ringel, Li Xu, Lambertus A. Kiemeney (D, Huiling He, Romana T. Netea-Maier (D), Jose I. Mayordomo, Theo S. Plantinga (D, Jon Hrafnkelsson, Hannes Hjartarson, Erich M. Sturgis, Aarno Palotie, Mark Daly, Cintia E. Citterio (D), Peter Arvan, Chad M. Brummett, Michael Boehnke (1), Albert de la Chapelle (D), Kari Stefansson (1), Kristian Hveem, Cristen J. Willer (1) \& Bjørn Olav Åsvold (1)

Correction to: Nature Communications https://doi.org/10.1038/s41467-020-17718-z, published online 07 August 2020.

The original version of this article contained an error in the results, in the second paragraph of the subsection entitled "Fine-mapping for potentially causal variants among TSH loci”, in which effect sizes for two variants were incorrectly reported.

The original version incorrectly read 'In the HUNT study, the missense variant TG p.G67S (rs116340633, MAF $=1.8 \%$, effect size $=0.77 \mathrm{SD}, 95 \% \mathrm{CI}=0.73-0.82 \mathrm{SD}, P$-value $\left.=1.07 \times 10^{-21}\right)$ is in strong $\mathrm{LD}\left(r^{2}=0.99\right)$ with the most strongly associated variant rs117074997 (intronic). At the other association signal, missense variant TG p.P118L (rs114322847, MAF $=2.4 \%$, effect size $=0.84$ SD, $95 \% \mathrm{CI}=0.82-0.87 \mathrm{SD}, P$-value $\left.=1.87 \times 10^{-26}\right)$ is in strong LD $\left(r^{2}=0.92\right)$ with the most strongly associated variant $\mathrm{rs} 118039499$ (intronic) (Supplementary Table 2 and Supplementary Fig. 4)'.

The correct version replaces this sentence with 'In the HUNT study, the missense variant TG p.G67S (rs116340633, MAF $=1.8 \%$, effect size $=-0.26 \mathrm{SD}, 95 \% \mathrm{CI}=-0.31$ to $-0.20 \mathrm{SD}, P$-value $\left.=1.07 \times 10^{-21}\right)$ is in strong $\mathrm{LD}\left(r^{2}=0.99\right)$ with the most strongly associated variant rs117074997 (intronic). At the other association signal, missense variant TG p.P118L (rs114322847, MAF $=2.4 \%$, effect size $=-0.17 \mathrm{SD}, 95 \% \mathrm{CI}=-0.20$ to $-0.14 \mathrm{SD}, P$-value $\left.=1.87 \times 10^{-26}\right)$ is in strong $\mathrm{LD}\left(r^{2}=0.92\right)$ with the most strongly associated variant rs118039499 (intronic) (Supplementary Table 2, Supplementary Figure 4)'.

This has been corrected in both the PDF and HTML versions of the Article.

Published online: 16 December 2021 
(c) Open Access This article is licensed under a Creative Commons Attribution 4.0 International License, which permits use, sharing, adaptation, distribution and reproduction in any medium or format, as long as you give appropriate credit to the original author(s) and the source, provide a link to the Creative Commons license, and indicate if changes were made. The images or other third party material in this article are included in the article's Creative Commons license, unless indicated otherwise in a credit line to the material. If material is not included in the article's Creative Commons license and your intended use is not permitted by statutory regulation or exceeds the permitted use, you will need to obtain permission directly from the copyright holder. To view a copy of this license, visit http://creativecommons.org/licenses/by/4.0/.

(C) The Author(s) 2021 